\title{
Mid-upper tropospheric methane retrieval from IASI and its validation
}

\author{
X. Xiong ${ }^{1,2}$, C. Barnet ${ }^{2}$, E. S. Maddy ${ }^{2,3}$, A. Gambacorta ${ }^{1,2}$, T. S. King ${ }^{1,2}$, and S. C. Wofsy ${ }^{4}$ \\ ${ }^{1}$ IMSG at NOAA Center for Satellite Applications and Research, College Park, MD, USA \\ ${ }^{2}$ National Environmental Satellite, Data, and Information Service, NOAA, USA \\ ${ }^{3}$ Science and Technology Corporation, Langley, VA, USA \\ ${ }^{4}$ Department of Earth and Planetary Sciences, Harvard University, Cambridge, MA, USA
}

Correspondence to: X. Xiong (xiaozhen.xiong@noaa.gov)

Received: 31 December 2012 - Published in Atmos. Meas. Tech. Discuss.: 11 March 2013

Revised: 22 July 2013 - Accepted: 23 July 2013 - Published: 3 September 2013

\begin{abstract}
Mid-upper tropospheric methane $\left(\mathrm{CH}_{4}\right)$, as an operational product at NOAA's (National Oceanic and Atmospheric Administration) Comprehensive Large Array-data Stewardship System (CLASS), has been retrieved from the Infrared Atmospheric Sounding Interferometer (IASI) since 2008. This paper provides a description of the retrieval method and the validation using $596 \mathrm{CH}_{4}$ vertical profiles from aircraft measurements by the HIAPER Pole-to-Pole Observations (HIPPO) program over the Pacific Ocean. The number of degrees of freedom for the $\mathrm{CH}_{4}$ retrieval is mostly less than 1.5, and it decreases under cloudy conditions. The retrievals show greatest sensitivity between $100-600 \mathrm{hPa}$ in the tropics and $200-750 \mathrm{hPa}$ in the mid- to high latitude. Validation is accomplished using aircraft measurements (convolved by applying the monthly mean averaging kernels) collocated with all the retrieved profiles within $200 \mathrm{~km}$ and on the same day, and the results show that, on average, a larger error of $\mathrm{CH}_{4}$ occurs at 300-500 $\mathrm{hPa}$. The bias in the trapezoid of $374-477 \mathrm{hPa}$ is $-1.74 \%$ with a residual standard deviation of $1.20 \%$, and at layer $596-753 \mathrm{hPa}$ the bias is $-0.69 \%$ with a residual standard deviation of $1.07 \%$. The retrieval error is relatively larger in the high northern latitude regions and/or under cloudy conditions. The main reasons for this negative bias include the uncertainty in the spectroscopy near the methane $Q$ branch and/or the empirical bias correction, plus residual cloud contamination in the cloud-cleared radiances. It is expected for NOAA to generate the $\mathrm{CH}_{4}$ product for 20 + years using a similar algorithm from three similar thermal infrared sensors: Atmospheric Infrared Sounder (AIRS), IASI and the Cross-track Infrared Sounder (CrIS).
\end{abstract}

Such a unique product will provide a supplementary to the current ground-based observation network, particularly in the Arctic, for monitoring the $\mathrm{CH}_{4}$ cycle, its transport and trend associated with climate change.

\section{Introduction}

As one of the most important greenhouse gases after carbon dioxide $\left(\mathrm{CO}_{2}\right)$, atmospheric methane $\left(\mathrm{CH}_{4}\right)$ is 25 times more effective on a per unit mass basis than carbon dioxide in absorbing long-wave radiation on a 100-year time horizon, and accounts for $18 \%$ of the total of $2.66 \mathrm{~W} \mathrm{~m}^{-2}$ of the anthropogenically produced greenhouse gas radiative forcing (IPCC, 2007). It also plays an important role in atmospheric ozone chemistry (e.g., in the presence of nitrogen oxides, tropospheric methane oxidation will lead to the formation of ozone) and in enriching moisture in the stratosphere (e.g., Brasseur et al., 1998). The concentration of $\mathrm{CH}_{4}$ in the atmosphere has increased from the pre-industrial levels of about 700 parts per billion (ppb) to about $1800 \mathrm{ppb}$. However, it experienced a nearly stable period of about one decade (e.g., Dlugokencky et al., 2003; Simpson et al., 2002) before a renewed increase was found in 2007 and the following years (Rigby et al., 2008; Dlugokencky et al., 2009; Sussmann et al., 2012). While the recent increase of $\mathrm{CH}_{4}$ in 2007-2008 is most likely attributed to the increased emissions from tropical and Arctic wetlands (Rigby et al., 2008; Dlugokencky et al., 2009), many uncertainties regarding natural methane emissions still exist, and one major concern is the amount of 
$\mathrm{CH}_{4}$ potentially released from permafrost soils and continental shelves in the future, a likely positive feedback of Arctic warming (Zimov et al., 2006; Shakhova et al., 2010; Kort et al., 2012).

The primary data used as a constraint for model simulations to quantify the global $\mathrm{CH}_{4}$ sources and sinks are highprecision in situ measurements of $\mathrm{CH}_{4}$ mixing ratios (e.g., Chen and Prinn, 2006; Bousquet et al., 2006, 2011) and the $\mathrm{CH}_{4}$ isotopes, and these data have been acquired at the sites of NOAA/ESRL/GMD (National Oceanic and Atmospheric Administration, Earth System Research Laboratory, Global Monitoring Division) networks and some other sites under the umbrella of the WMO (World Meteorological Organization) Global Atmosphere Watch (GAW) programme for more than $25 \mathrm{yr}$. However, quantification of different emission source types and source regions still has large uncertainties, due to a large spatial and temporal variation of different $\mathrm{CH}_{4}$ emission sources and the sparseness of ground observational networks, particularly in the polar regions (Zhuang et al., 2009). Recent satellite observations provide measurements of $\mathrm{CH}_{4}$ with a large spatial and temporal coverage, and they can be used as an additional constraint for inverse modeling (e.g., Wecht et al., 2012).

Spaceborne measurements of $\mathrm{CH}_{4}$ include the use of thermal infrared (TIR) sounders (with the largest sensitivity to the mid-upper tropospheric $\mathrm{CH}_{4}$ ), near-IR (NIR) measurements (with the largest sensitivity to the total column amount of $\mathrm{CH}_{4}$ ), and limb sounding (with sensitivity to $\mathrm{CH}_{4}$ in the upper troposphere and stratosphere). The TIR observations of the $\mathrm{CH}_{4}$ profile include the Interferometric Monitor for Greenhouse Gases (IMG) onboard the Advanced Earth Observing Satellite (ADEOS) (Clerbaux et al., 2003), the Tropospheric Emission Spectrometer (TES) on NASA/Aura (Payne et al., 2009; Wecht et al., 2012; Worden et al., 2012), the Atmospheric Infrared Sounder (AIRS) on NASA/AQUA (Aumamn et al., 2003; Xiong et al., 2008, 2009, 2010a,b), and the Infrared Atmospheric Sounding Interferometer (IASI) on MetOp-A (Crevoisier et al., 2009; Razavi et al., 2009). The NIR observations of $\mathrm{CH}_{4}$ total column include the SCanning Imaging Absorption spectroMeter for Atmospheric CHartographY (SCIAMACHY) instrument onboard ENVISAT for 2003-2009 (e.g., Frankenberg et al., 2008, 2011), and the Thermal And Near infrared Sensor for carbon Observation (TANSO) onboard the Greenhouse gases Observation SATellite (GOSAT) from 2009 to present, which carries the Fourier transform spectrometer (TANSO-FTS) to make both NIR and TIR observations (Yokota et al., 2009; Parker et al., 2011; Schepers et al., 2012). Spaceborne observations working in a limb geometry include ACE-FTS (e.g., De Maziere et al., 2008), HALOE (e.g., Park et al., 2004) and MIPAS (e.g., Payan et al., 2009).

Retrievals of $\mathrm{CH}_{4}$ from IASI have been successfully made before (for example, Crevoisier et al., 2009; Razavi et al., 2009), but using different algorithms from that used in the NOAA system. Crevoisier et al. (2009) reported their first retrieval results for one year in clear sky and tropical ocean condition based on neural networks. Nine strong $\mathrm{CH}_{4}$ absorption channels in the wavelength range of 1301$1305 \mathrm{~cm}^{-1}$ were used. Recent validation by Crevoisier et al. (2013) indicated that IASI can capture well the evolution of mid-tropospheric methane in the tropics. Razavi et al. (2009) reported some characteristics of methane retrievals based on the optimal estimation method (Rodgers, 2000) and used channels in the spectral range from 1240 to $1290 \mathrm{~cm}^{-1}$ (the channels in the $Q$ branch located near $1306 \mathrm{~cm}^{-1}$ were avoided). Using an algorithm similar to that in AIRS-V5 (Xiong et al., 2008), NOAA has been generating $\mathrm{CH}_{4}$ profiles using IASI data since 2008. Due to the uncertainties in the satellite remote sensing resulting from many factors associated with the radiative transfer modeling in the atmosphereEarth system, and observational noise, validation of the IASI $\mathrm{CH}_{4}$ profile through comparison with aircraft measurements is vital for the users to understand the uncertainties of this product, so as to better use this product in their research. Therefore, in this study we validate the NOAA IASI $\mathrm{CH}_{4}$ product using aircraft measurements from the HIAPER Poleto-Pole Observations (HIPPO) program from all five campaigns. Section 2 gives a brief introduction of the IASI instrument, the retrieval methodology and some characteristics of the retrieval product. Section 3 describes the aircraft measurements data, the method of validation including the application of monthly mean averaging kernels, and the detailed validation results. A discussion and summary are given in Sect. 4.

\section{The IASI Instrument and the methane retrieval}

\subsection{Description of IASI instrument and the NOAA retrieval system}

The IASI is a cross-track-scanning Michelson interferometer that measures 8461 channels at $0.25 \mathrm{~cm}^{-1}$ spacing in three bands between 645 to $2760 \mathrm{~cm}^{-1}$ in a $2 \times 2$ array of circular footprints with a nadir spatial resolution of roughly $50 \mathrm{~km} \times 50 \mathrm{~km}$ (with a corresponding single footprint spatial resolution at nadir of roughly $12 \mathrm{~km}$ ). IASI on the MetOp-A platform of the European Organization for the Exploitation of Meteorological Satellites (EUMETSAT) was launched into a $817 \mathrm{~km}$-altitude polar orbit on 19 October 2006, and MetOp-B was launched on 17 September 2012. The satellite crosses the Equator at approximately 09:30 and 21:30 LT, resulting in near-global coverage twice a day. The on-flight noise-equivalent delta temperature (NEDT) at $280 \mathrm{~K}$ has been estimated to be well below $0.1 \mathrm{~K}$ in the spectral range of methane (Razavi et al., 2009). Like AIRS, IASI has a wide swath with a scan angle of $\pm 48.3^{\circ}$. Its nominal scan line covers 30 scan positions towards the Earth with four instantaneous fields of view (IFOV). An advanced microwave sounding unit (AMSU) is also flying on the MetOp-A platform, 
and in the NOAA retrieval system both IASI and AMSU are used, in order to allow for retrieval in both clear and partially cloudy conditions (Maddy et al., 2011, 2012). IASI level 1c and AMSU level $1 \mathrm{~b}$ data have been available since July 2007.

The IASI retrieval system at NOAA/NESDIS was built to emulate the AIRS-V5 retrieval system, and has been put into operation at NOAA's CLASS since 2008 (Maddy et al., 2009). More details about the AIRS retrieval system (V5) can be found in Susskind et al. (2003) and the references therein. The NOAA IASI retrieval system is a sequential retrieval using both IASI and AMSU observations, including the steps of microwave-only retrieval, cloud clearing, initial IR retrieval, and a final physical retrieval. The $\mathrm{CH}_{4}$ retrieval is performed on the basis of successful retrievals of the water vapor profile, the temperature profile and surface characteristics, and can work under clear and partially cloudy conditions. Under partially cloudy conditions, we used the cloud-cleared radiance, which was derived by using 4 IASI FOV contained in each single AMSU FOV for removing the effect of clouds on the IASI-observed infrared radiance. These products, including $\mathrm{CH}_{4}$, are currently available at the NOAA CLASS (http://www.nsof.class.noaa.gov/ saa/products/search?datatype_family=IASI).

\subsection{Retrieval method and its optimization}

Similar to the AIRS $\mathrm{CH}_{4}$ retrieval (Xiong et al., 2008), channels in the whole $\mathrm{CH}_{4}$ absorption band between 1200 and $1400 \mathrm{~cm}^{-1}$ that are sensitive to $\mathrm{CH}_{4}$ but insensitive to $\mathrm{N}_{2} \mathrm{O}$ and $\mathrm{HNO}_{3}$ were selected. Channels with strong absorption of $\mathrm{H}_{2} \mathrm{O}$ are also avoided. In the NOAA IASI retrieval system (V2), 60 IASI channels were selected, and they include both the strong $\mathrm{CH}_{4}$ channels near the $\mathrm{CH}_{4} Q$ branch, which are more sensitive to $\mathrm{CH}_{4}$ in the upper troposphere, as well as channels near $1230 \mathrm{~cm}^{-1}$ that are sensitive to the lower troposphere (Worden et al., 2012). In the $\mathrm{CH}_{4}$ retrieval, the atmospheric temperature profile, water profile, surface temperature and surface emissivity are required as inputs, and these variables are derived from other separate IASI/AMSU channels in separate steps. Figure 1 shows the change of brightness temperatures (BTs) in the IASI $\mathrm{CH}_{4}$ band corresponding to a change of the surface temperature by $+1.5 \mathrm{~K}$, of water vapor by $+10 \%$, and of $\mathrm{CH}_{4}$ by $+5 \%$ in the tropics using data on 8 November 2009. From Fig. 1 we can see that the impact of errors in surface temperature mainly affects the weak absorption channels below $1240 \mathrm{~cm}^{-1}$. The impact of water vapor is visible in the whole $\mathrm{CH}_{4}$ band, and the change of BTs corresponding to a $10 \%$ bias in the whole water vapor profile is almost equivalent to a $5 \%$ change in $\mathrm{CH}_{4}$ for many channels except in the $Q$ branch near $1306 \mathrm{~cm}^{-1}$. This indicates that it is important to use these 15-20 sensitive $\mathrm{CH}_{4}$ channels in the $Q$ branch, and a better retrieval of water vapor profile will improve the $\mathrm{CH}_{4}$ retrieval. The overall sensitivity of the $\mathrm{CH}_{4}$ retrieval to water vapor errors is further reduced

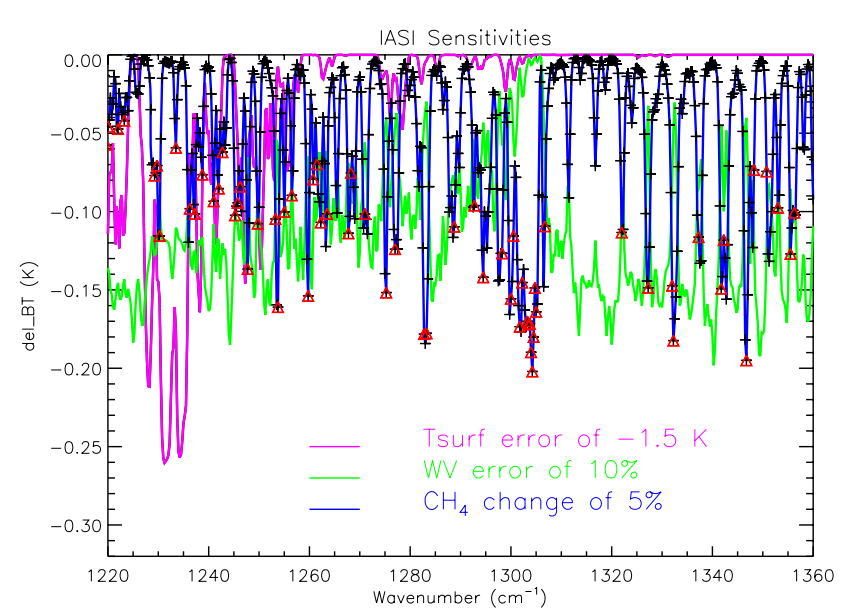

Fig. 1. Change of brightness temperatures (del_BT) in the IASI $\mathrm{CH}_{4}$ band corresponding to a change of surface temperature $\left(T_{\text {surf }}\right.$, $1.5 \mathrm{~K})$, water vapor (WV, $10 \%)$ and $\mathrm{CH}_{4}(5 \%)$ in the tropics using data on 8 November 2009. Red triangles are the channels used in the retrieval.

by giving less weight to the channel with a larger sensitivity to water vapor errors.

To input the atmospheric temperature profile, water profile, surface temperature, surface emissivity data and the $\mathrm{CH}_{4}$ first guess profile to the forward model (Strow et al., 2003), we can get the computed upwelling radiance. The difference between the computed radiance and the cloud cleared radiance, $\Delta \boldsymbol{R}$, is used to compute a change to the $\mathrm{CH}_{4}$ mixing ratio, $\Delta \boldsymbol{X}$, as follows:

$\Delta \boldsymbol{R}=\mathbf{S} \cdot \Delta \boldsymbol{X}+\boldsymbol{\Sigma}$,

where $\boldsymbol{\Delta} \boldsymbol{R}$ is a vector of radiances (observed minus computed) at $n$ different channels $\left(\Delta R_{n}\right)$, and $\Delta \boldsymbol{X}$ is a vector of differences of $\mathrm{CH}_{4}$ from the first guess profile at $L$ different levels $\left(\Delta X_{L}\right)$. $\mathbf{S}$ is a matrix with its elements $S_{n, L}$ representing the sensitivity of radiance in channel $n$ to a change of $\mathrm{CH}_{4}$ at level $L\left(\Delta X_{L}\right) . \Sigma$ is a vector that represents the errors at different channels. Equation (1) can be solved using singular value decomposition (SVD) of the covariance matrix of the sensitivity weighted by an inverse of the estimates of the precision and accuracy of our radiative transfer model and the errors and noise in the measurements. Damping the least significant eigenfunctions of the SVD to constrain the solution, the change in $\mathrm{CH}_{4}$ can be written as

$\boldsymbol{\Delta} \boldsymbol{X}=\mathbf{U} \cdot \Lambda \cdot \mathbf{U}^{T} \cdot \mathbf{S}^{T} \cdot \mathbf{W} \cdot(\boldsymbol{\Delta} \boldsymbol{R}-\boldsymbol{\Phi})$,

where $\mathbf{U}$ is a matrix with the eigenvectors from the SVD, $\mathbf{W}$ is an inverse matrix of the error and its elements represent the weight based on the estimated precision and accuracy of our radiative transfer model and the errors and noise in the measurements in channel $n, \boldsymbol{\Phi}$ is a background term (Susskind et al., 2003), and superscripted $T$ represents the transpose operator. $\Lambda$ is a diagonal matrix with its elements $\Delta \lambda /(\Delta \lambda+\lambda)$, 
Table 1. IASI trapezoid layers in retrieval $(\mathrm{hPa})$.

\begin{tabular}{ccccccccccccc}
\hline Level & 1 & 2 & 3 & 4 & 5 & 6 & 7 & 8 & 9 & 10 & 11 & 12 \\
\hline $\mathrm{hPa}$ & 0.016 & 11.0 & 96.1 & 151.3 & 223.4 & 300.0 & 374.7 & 478.0 & 596.3 & 753.6 & 904.8 & 1100.0 \\
\hline
\end{tabular}

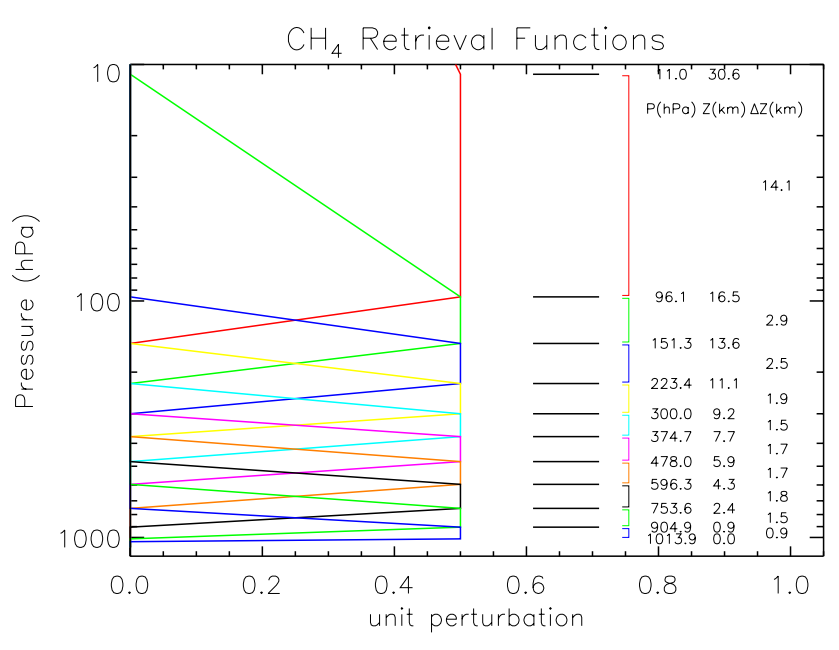

Fig. 2. The 11 trapezoidal perturbation functions for the IASI $\mathrm{CH}_{4}$ retrieval.

where $\Delta \lambda$ is the damping variable proportional to the eigenvalue $\lambda$ as defined in Eq. (4) of Maddy and Barnet (2008) and Eq. (3) of McMillan et al. (2011). This retrieval methodology minimizes the dependence of the solution to the a priori first guess profile and covariance matrix, and relies strongly on the signal to noise ratio of the observation. The eigenvalues, $\lambda$, give an indication of the usefulness of each component and are used to determine the damping variable in the retrieval. A more detailed description of this algorithm is found in Susskind et al. (2003) and Xiong et al. (2008).

As the information content of the IASI $\mathrm{CH}_{4}$ channels between 1200 and $1400 \mathrm{~cm}^{-1}$ is redundant and the largest sensitivities of these channels to $\mathrm{CH}_{4}$ are mostly limited to a broad layer near the mid- to upper troposphere, the IASI $\mathrm{CH}_{4}$ retrieval uses 11 layers (Table 1) that are set as a series of 11 vertically overlapping trapezoidal functions (Fig. 2).

The $\mathrm{CH}_{4}$ first guess profile ("a priori"), as described in Xiong et al. (2008), is given as a smoothed function of latitude and pressure (to capture its strong latitudinal and vertical gradients), but no temporal and longitudinal variations are introduced in the retrieval. Figure 3 shows examples of the first guess profiles at 5 different latitudes $\left(60^{\circ} \mathrm{S}, 30^{\circ} \mathrm{S}, 0\right.$, $30^{\circ} \mathrm{N}$ and $\left.60^{\circ} \mathrm{N}\right)$.

\subsection{Averaging kernels and the retrieval sensitivity}

The averaging kernels are defined to provide a simple characterization of the relationship between the retrieval and the true state. The retrieval sensitivity can be obtained from the

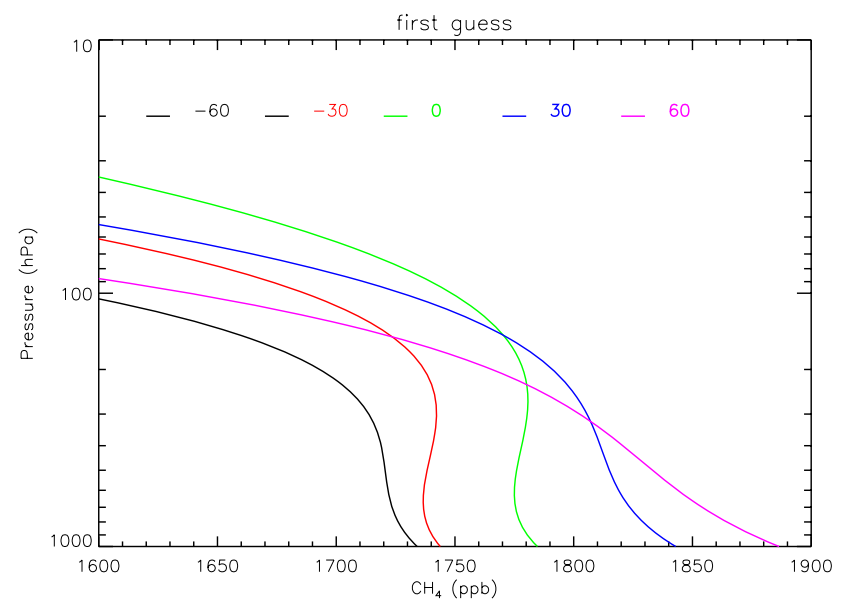

Fig. 3. Example of the first guess profiles in latitudes of $60^{\circ} \mathrm{S}$, $30^{\circ} \mathrm{S}, 0,30^{\circ} \mathrm{N}$ and $60^{\circ} \mathrm{N}$.
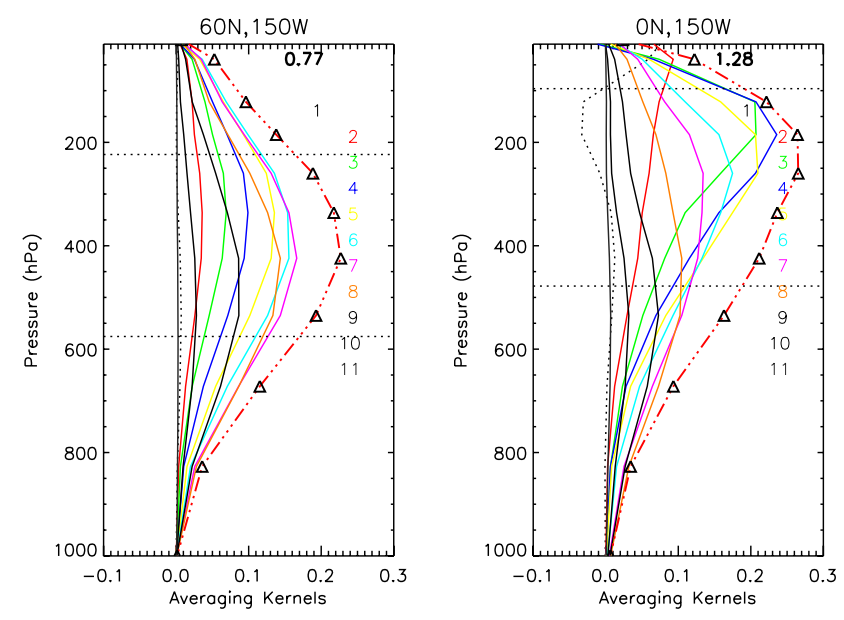

Fig. 4. The averaging kernels in the high Northern Hemisphere and the tropics over the Pacific Ocean in September 2009. Different colors correspond to 11 different trapezoid functions (see Table 1). In order to plot the area of the averaging kernels in the same range of $x$ axis, the red dash line is the area of the averaging kernels divided by 4 .

sum of the columns of the averaging kernel matrix, which is also referred to as "the area of the averaging kernel" (Rodgers, 2000). More details about the computation of averaging kernels can be found in Maddy and Barnet (2008) and Xiong et al. (2008). As an example, Fig. 4 shows the averaging kernels for the 11 trapezoidal functions in the high northern latitude and in the tropics in September 2009. It 


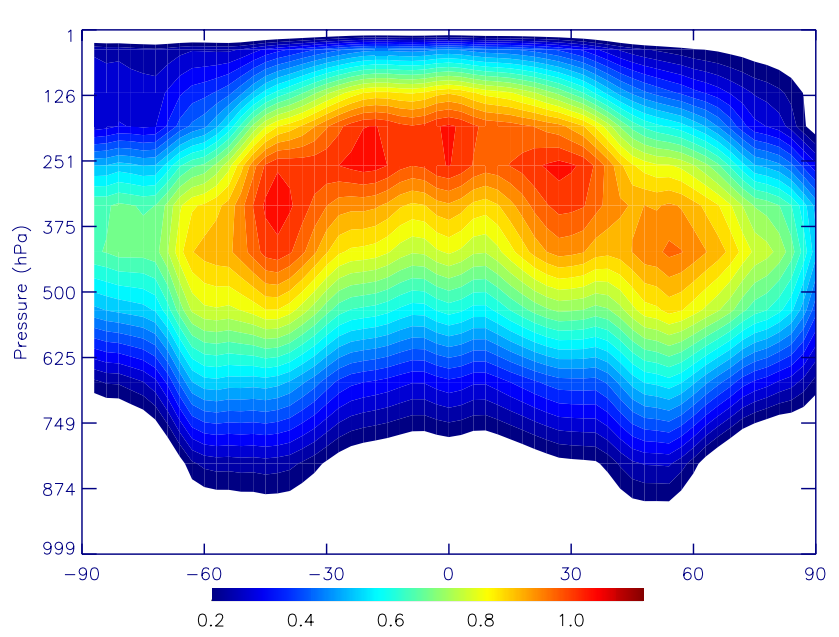

Fig. 5. Zonal mean of the area of averaging kernels. The $x$ axis is the latitude. The color bar represents the value of the area of the averaging kernels (no unit).

is evident that the averaging kernels corresponding to these 11 functions are broad and exhibit significant overlap, indicating that the retrieved amounts of $\mathrm{CH}_{4}$ at different layers are not independent. The degrees of freedom (DOF), defined as the fractional number of significant eigenfunctions used in the retrieval process and computed as the trace of the averaging kernel matrix, is about 1.28 in the tropics and 0.98 in the high Northern Hemisphere in this case. In general, the DOF in the tropics is higher than in the high latitudes, and in the summer is higher than in winter.

To better see the retrieval sensitivity in different latitudes, Fig. 5 shows the contour map of the area of the averaging kernels as a function of latitude and pressure. From Fig. 5 we can see that the sensitivity near the tropics is largest between 100 and $600 \mathrm{hPa}$, while in the mid-high latitude regions it is largest between 200 and $750 \mathrm{hPa}$. Due to the impact of the temperature and moisture profiles, the vertical sensitivity of the retrieval has large geographic and seasonal variability.

\subsection{Quality flag}

To make sure a stable retrieval result is used in the validation and future data analysis, an appropriate quality control is required. From the experiences we learned, a retrieved profile meeting the following criteria is of good quality and recommended for use:

1. both infrared and microwave retrievals of water vapor and temperature are successful;

2. residual (observation minus computation from Radiative Transfer Algorithm, RTA) relative to the estimated errors (including error in instrument, cloud-clearing, forward model), as represented by the quantity $\chi^{2}$, is less than $3\left(\chi^{2}<3\right) \cdot \chi^{2}$ is computed as below. $N$ is the total number of channels used for $\mathrm{CH}_{4}$ retrieval

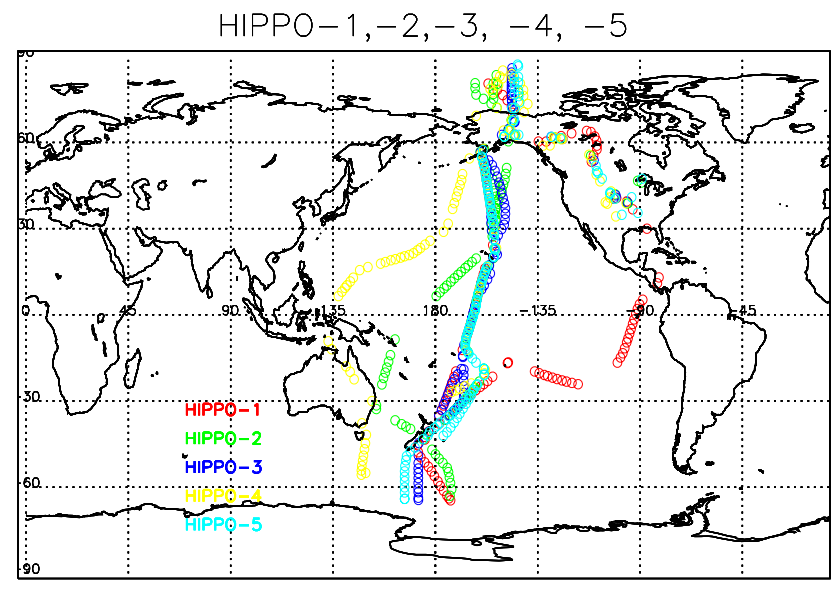

Fig. 6. Locations and numbers of aircraft measurement profiles selected for validation from HIPPO-1 (red, $N=121$ ), HIPPO2 (green, $N=121$ ), HIPPO-3 (blue, $N=88$ ), HIPPO-4 (yellow, $N=121)$ and HIPPO-5 (cyan, $N=145)$.

$$
\chi^{2}=\left\{\left[\sum_{n=1}^{N}\left(\Delta R_{n} \Delta R_{n}\right) / W_{n, n}\right] / N\right\}^{1 / 2}
$$

3. total field of regard (FOR) cloud fraction, solving for two layers of clouds, is less than 1.5;

4. DOF is greater than 0.4 .

\section{Validation}

\section{1 $\mathrm{CH}_{4}$ profiles from HIPPO-1, $-2,-3,-4$, and -5 aircraft measurement campaigns}

Aircraft measurements of the $\mathrm{CH}_{4}$ vertical profiles by the HIAPER Pole-to-Pole Observations (HIPPO) program over the Pacific Ocean (Wofsy et al., 2011) provide a unique dataset for validation over a wide latitudinal range $\left(67^{\circ} \mathrm{S}-85^{\circ} \mathrm{N}\right)$. Figure 6 shows the flight paths of the National Science Foundation's Gulfstream V (GV) during all the five HIPPO missions in January 2009 (HIPPO-1), October-November 2009 (HIPPO-2), March-April 2010 (HIPPO-3), June-July 2011 (HIPPO-4) and August-September 2011 (HIPPO-5), with the location of the selected aircraft measurements. The GV transected the Pacific Ocean from $85^{\circ} \mathrm{N}$ to $67^{\circ} \mathrm{S}$, performing in-progress vertical profiles every $220 \mathrm{~km}$ or $20 \mathrm{~min}$ (Wofsy et al., 2011). $\mathrm{CH}_{4}$ was measured with a quantum cascade laser spectrometer (QCLS) at $1 \mathrm{~Hz}$ frequency with an accuracy of $1.0 \mathrm{ppb}$ and a precision of $0.5 \mathrm{ppb}$ (Kort et al., 2012). HIPPO methane data are reported on the NOAA04 calibration scale. The NOAA04 scale was designated as the official calibration scale, and consists of 16 gravimetrically prepared primary standards covering the nominal range of 300 to $2600 \mathrm{nmol} \mathrm{mol}^{-1}$ (Dlugokencky et al., 2005). This new scale 
results in $\mathrm{CH}_{4}$ mole fractions that are a factor of 1.0124 greater than the previous scale (now designated CMDL83). We isolated each vertical profile performed by the GV based on the flight distance and height.

Similar to the validation of TES observations by Wecht et al. (2012), for each HIPPO vertical profile (covering $220 \mathrm{~km}$ in $20 \mathrm{~min}$ ), we calculated the mean location (latitude and longitude) and time. All IASI retrievals coincident with a HIPPO profile in a collocation window with a distance of $200 \mathrm{~km}$ and on the same day and passing the quality control check were used to compute the mean profile, which is then compared to the corresponding HIPPO aircraft profile after applying the averaging kernels, as described later.

\subsection{Method of validation}

In order to take into account the low vertical resolution of the $\mathrm{CH}_{4}$ retrievals, the averaging kernels need to be applied to the in situ aircraft data for validating the retrieved profile from IASI. This can be done based on the following equation:

$\hat{\boldsymbol{x}}=\mathbf{A} \boldsymbol{x}+(\mathbf{I}-\mathbf{A}) \boldsymbol{x}_{\mathrm{a}}$,

where $\mathbf{I}$ is the identity matrix, $\mathbf{A}$ the averaging kernel matrix, $\boldsymbol{x}_{\mathrm{a}}$ the first guess profile (unit: part per billion, ppb), $\boldsymbol{x}$ the in situ aircraft measurement profile, and the computed value of $\hat{\boldsymbol{x}}$ is referred to as the convolved data later in this paper and will be compared with the retrieved $\mathrm{CH}_{4}$ mixing ratio. Note that we need to take the logarithm to $\boldsymbol{x}, \boldsymbol{x}_{\mathrm{a}}, \hat{\boldsymbol{x}}$ when applying the averaging kernels (see Xiong et al., 2008).

As the aircraft profiles do not span the entire vertical range defined by the IASI averaging kernels, extension of the aircraft profiles is required, and usually this is done using output from a chemistry model or a climatology to represent the upper troposphere and higher levels. In this paper we used the monthly averaged $\mathrm{CH}_{4}$ data from 2007 from an atmospheric general circulation model (AGCM)-based chemistry transport model (hereinafter ACTM) (Patra et al., 2011) to extrapolate from the ceiling of the aircraft profile to the top of atmosphere and from the lowest measurement height to the bottom of the atmosphere. The profile is then mapped to the 100-level grid of the RTA (Strow et al., 2003). HIPPO aircraft profiles with ceilings lower than $350 \mathrm{hPa}$ were not used.

As the averaging kernels are not included in the NOAA CLASS output, we used the monthly mean averaging kernels that were generated in the course of our data processing and saved as a $3^{\circ} \times 3^{\circ}$ grid product. The error due to the use of the mean averaging kernels $(\overline{\mathbf{A}})$ instead of the actual kernels (A) can be estimated as

$\Delta \hat{\boldsymbol{x}}=(\mathbf{A}-\overline{\mathbf{A}})\left(\boldsymbol{x}-\boldsymbol{x}_{\mathrm{a}}\right)$.

We found that the difference between $\boldsymbol{x}_{\mathrm{a}}$, the first guess, and $\boldsymbol{x}$, in situ aircraft measurement profile from HIPPO, is mostly less than $3 \%$. With an estimate of the variation of averaging
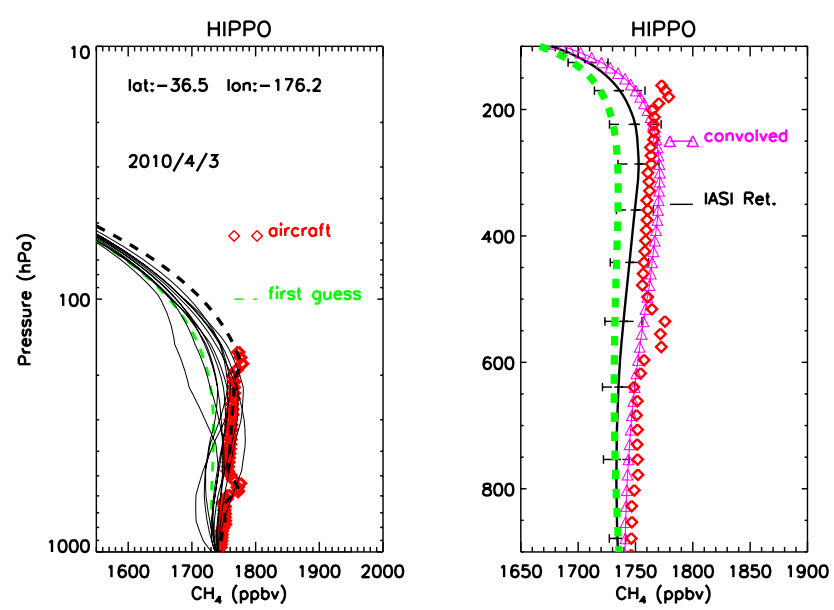

Fig. 7. $\mathrm{A} \mathrm{CH}_{4}$ profile on 3 April 2010 by HIPPO-3 aircraft measurement (red dots) vs. all IASI retrievals in a collocation window with a distance of $200 \mathrm{~km}$ and on the same day. The right panel is the mean profile of IASI retrievals with the bars showing the standard deviation, the aircraft measurements smoothed with the averaging kernels (AK) (pink, triangles), and the first guess profile (green dash line).

kernels within one month of less than $20 \%$, the error due to the use of the mean averaging kernels is less than $0.6 \%$. In this study, the averaging kernel in the grid point closest to the in situ observation is selected to convert the corresponding aircraft profile. The averaging kernels matrix $(11 \times 11)$ is also mapped to $100 \times 100$ (Maddy and Barnet, 2008), so the retrieved profiles and the convolved data can be compared at the 100-level grid of RTA and the coarse layers of the trapezoid functions.

\subsection{Results}

As an example to illustrate the validation procedure, Fig. 7 shows the comparison of one HIPPO profile in the midlatitude in 3 April 2010 with all accepted IASI retrievals in a collocation window with a distance of $200 \mathrm{~km}$ and on the same day. Comparison of the mean IASI-retrieved profile with the profile from aircraft measurements (both the original and convolved profiles are shown) indicates that they are in a good agreement, except that the retrieved profile is smoother and cannot capture the fine vertical structure seen in aircraft measurements, for example near $500-600 \mathrm{hPa}$. This is understandable as the retrieved profile at each layer represents a weighted average of the real profile smoothed over its surrounding layers. Compared to the first guess, the IASIretrieved mean profile is closer to the in situ aircraft observations at its sensitive layer between 200 and $650 \mathrm{hPa}$.

Results of the statistical analysis of the validation results using all 596 profiles from five campaigns of HIPPO are shown in Fig. 8. Comparisons in four trapezoid layers of 300-374, 374-477, 477-596 and 596-753 hPa are illustrated (data above $300 \mathrm{hPa}$ are not shown due to lack of 

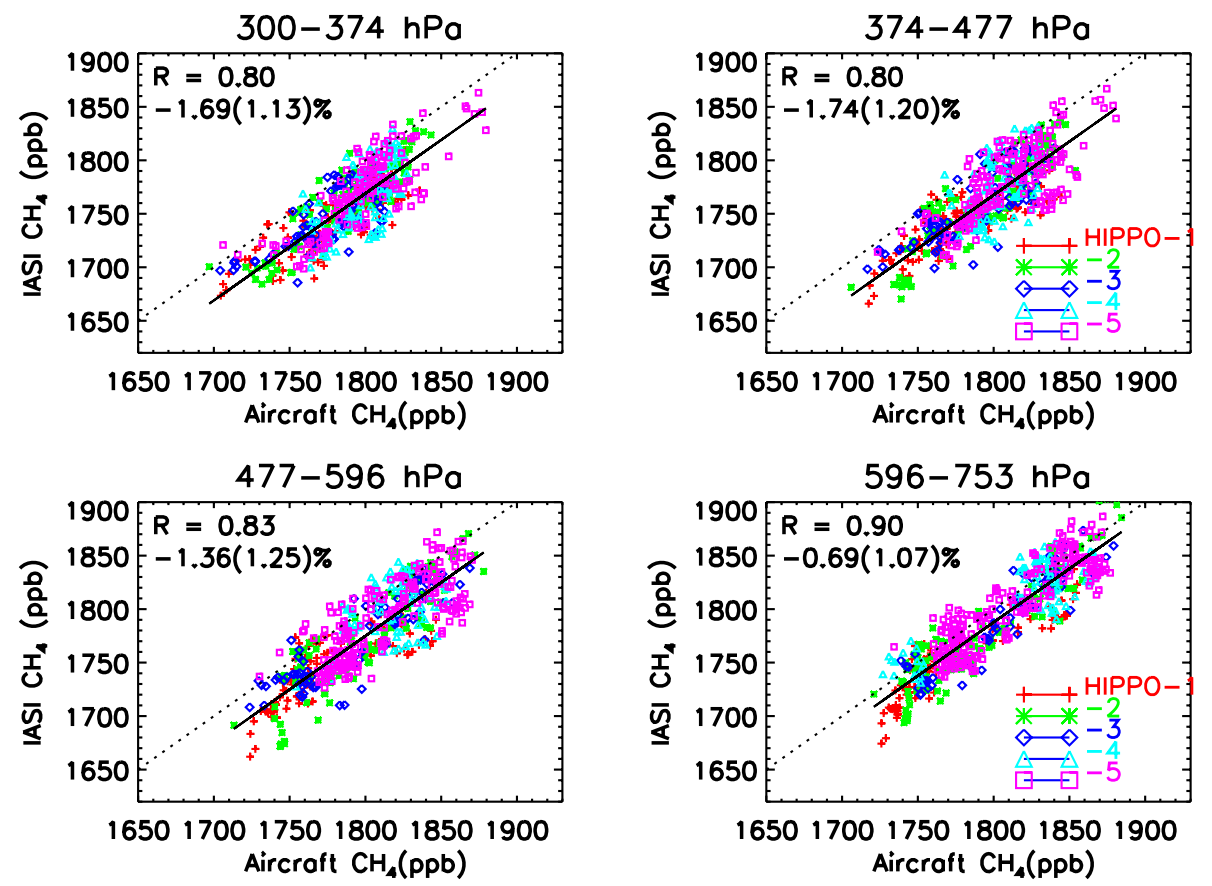

Fig. 8. IASI-retrieved $\mathrm{CH}_{4}$ mixing ratios plotted against aircraft profiles from HIPPO-1, $-2,-3,-4$ and -5 in four trapezoid layers of 300-374, $374-477,477-596$ and 596-753 hPa. The $x$ axis is the convolved aircraft measurements, and the $y$ axis is the mean of IASI-retrieved profiles within $200 \mathrm{~km}$ and on the same day of the measurement time and site location. Different colors are from different campaigns of HIPPO. $R$ is the correlation coefficient, and the numbers below are the bias and residual standard deviation, respectively, in percent.

in situ aircraft measurements). Overall, the correlation between the IASI retrievals and the aircraft measurements is very good $(0.80-0.89)$, but IASI retrievals have a low bias between -0.69 and $-1.74 \%$ as compared to the in situ aircraft measurements (convolved), and the residual standard deviations are between 1.07 and $1.25 \%$. From Fig. 8 we cannot see significant differences of the errors among different campaigns of HIPPO, which were taken in different seasons. However, on average the bias from HIPPO-1 in January 2009 is the largest, particularly in the high Northern Hemisphere. We found this large bias is associated with the small DOF during the cold winter in the Arctic region.

The mean bias and RMS error of the retrieval in $100 \mathrm{lev-}$ els are shown in Fig. 9. For comparison the error of the first guess profile is also plotted. A larger negative bias occurs between 300 and $500 \mathrm{hPa}$, while below $500 \mathrm{hPa}$, both the bias and RMS errors are smaller than the first guess error. As expected, the errors of the convolved data are smaller than those without applying the averaging kernels (Xiong et al., 2008). A larger retrieval bias than the first guess bias in the upper atmosphere (Fig. 9) is most likely due to the uncertainty in the spectroscopy near methane $Q$ branch, errors in the RTA, and errors in the empirical bias correction to the radiance. Current bias correction was pre-computed as the difference of IASI-observed radiance minus the RTA computation using night ocean cases, for which the knowledge about the atmospheric profile and surface emissivity is the best. These
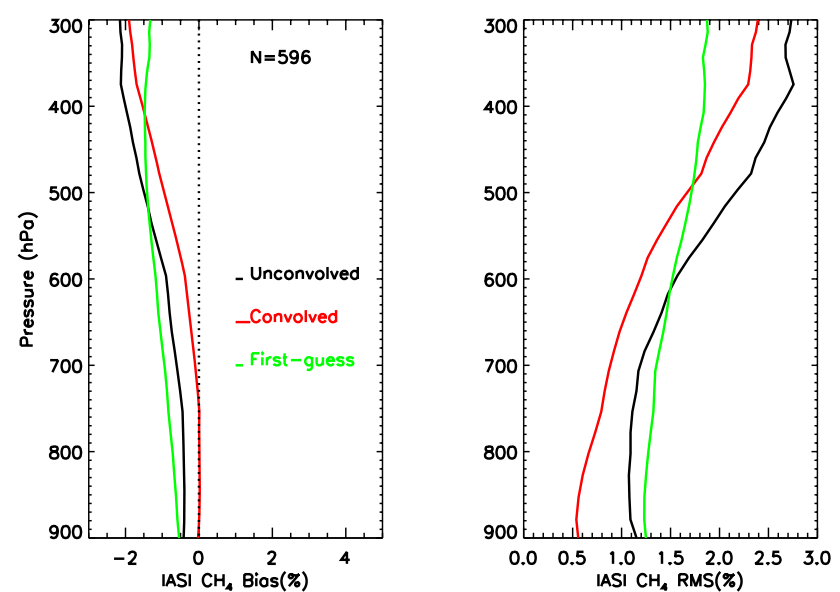

Fig. 9. Bias (left panel) and RMS errors (right panel) of the IASIretrieved $\mathrm{CH}_{4}$ mixing ratio and the first guess profile as compared to aircraft profiles from HIPPO.

bias correction data were applied to the radiances globally and not to the absorption coefficients in the RTA. Improvement in the future version can be made by using more aircraft measurements of trace gas profiles as truth, and the correction will be made to both the absorption coefficients and the radiance, and the best one will be used in application. Of course, the error from the extrapolation of the aircraft measurements from its ceiling to the top of atmosphere cannot 

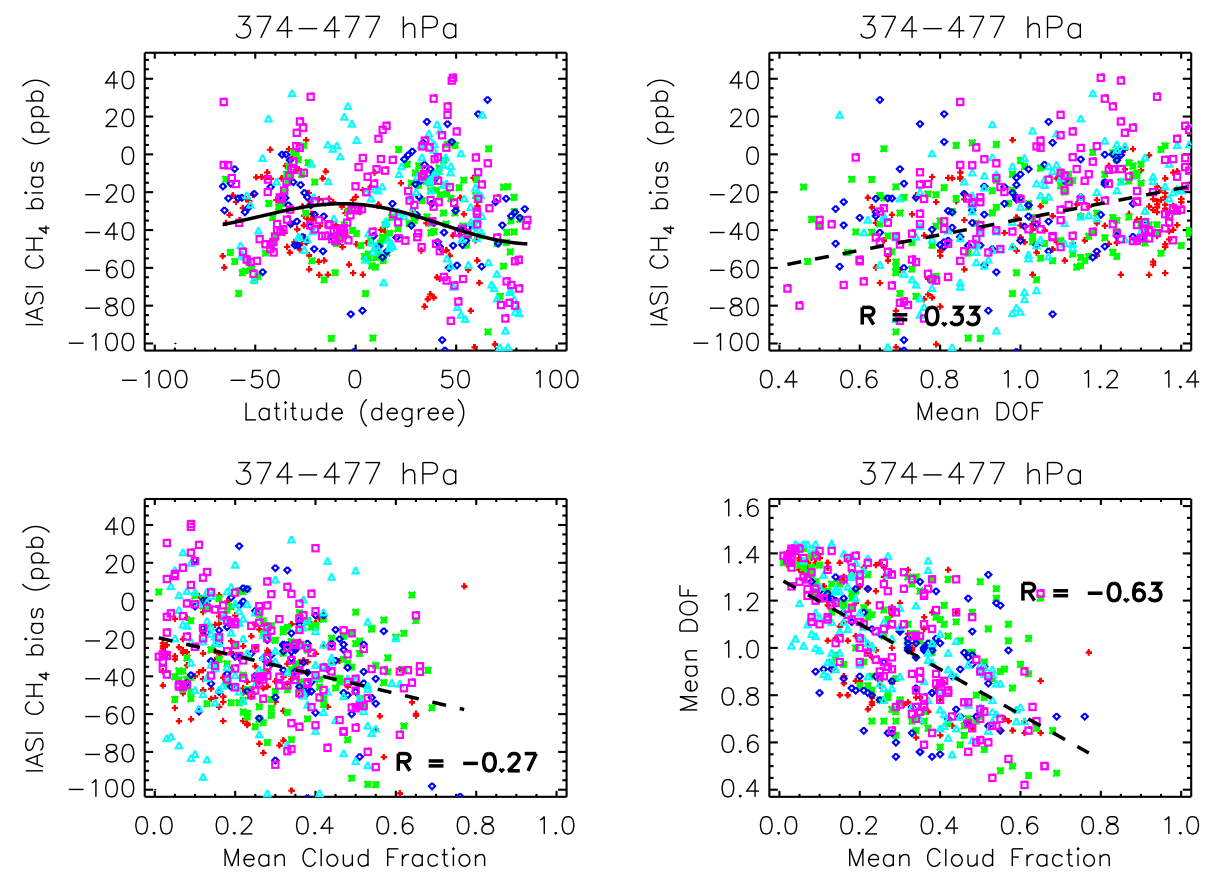

Fig. 10. Dependence of the IASI $\mathrm{CH}_{4}$ retrieval bias in layer $374-477 \mathrm{hPa}$ on latitude (the solid line is the second-order polynomial fitting of the error with latitude), and correlation between the IASI $\mathrm{CH}_{4}$ retrieval bias and mean degrees of freedom (DOF) and cloud fraction, and correlation between the mean DOF and cloud fraction. Similar results are found for other trapezoids. Different colors are for different campaigns as defined in Fig. 8.

be ignored, and, if possible, using model data on the same day can help to reduce this error. Some error results from the time difference between the measurement of MetOp-A (usually 09:30 and 21:30 LT) and aircraft measurement. However, this error is expected to be small, as already examined by Wecht et al. (2012).

Examination of the retrieval error (IASI - convolved in situ) in different latitudes (upper left) of Fig. 10 shows that the retrieval error in the high northern latitudes is slightly larger than in the tropics and the Southern Hemisphere. To better understand the error sources, we examined the correlation of the retrievals with a couple of parameters. We found the results for the four trapezoids in Fig. 8 are similar, so only the results at the trapezoid $374-477 \mathrm{hPa}$ are shown in Fig. 10. There is some correlation between the retrieval error with the degrees of freedom ( $R=0.33$, upper right of Fig. 10), and if we used the non-convolved aircraft data, i.e., the error (IASI - in situ), the correlation coefficient $R$ is 0.51 . This indicates that the convolution procedure using the averaging kernels successfully removes the dependence of the error on the information content and some first guess bias from the matchup (McMillian et al., 2011). There is a slight negative correlation between the retrieval error and cloud cover fraction $(R=-0.27)$, indicating the impact of cloud contamination on the retrieval. The correlation between the cloud fraction and the degrees of freedom is large $(R=-0.63)$. Thus, as the scene becomes more cloudy, the IASI $\mathrm{CH}_{4}$ retrieval sees less of the variation of $\mathrm{CH}_{4}$ and the DOF decreases.

\section{Discussion and summary}

As an operational product in the NOAA CLASS system, $\mathrm{CH}_{4}$ profiles have been retrieved using IASI data since 2008. To help users utilize this product appropriately, this paper provided the first validation of the NOAA $\mathrm{CH}_{4}$ product from IASI retrievals using 596 profiles from all five HIPPO aircraft measurement campaigns. The recommended setting of quality flags is also given.

Overall, the number of degrees of freedom for the IASI $\mathrm{CH}_{4}$ retrieval is less than 1.5 , and the information content in the tropics is higher than in high latitude regions. The sensitivity of IASI is largest between 100 and $600 \mathrm{hPa}$ in the tropics, and between 200 and $750 \mathrm{hPa}$ in the midto high latitudes. Validation using HIPPO aircraft measurements showed a large bias of nearly $-1.74 \%$ for the layer $374-477 \mathrm{hPa}$, and a small bias of $-0.69 \%$ for the layer $596-$ $753 \mathrm{hPa}$. The largest bias occurs in winter (HIPPO-1). The error also has some dependence with latitude and cloud cover, and it is larger in the high northern latitude regions and/or under cloudy conditions. However, these validated cases are mostly over the ocean, and the retrieval errors over the land are likely a little larger because over the ocean the surface emissivity is well known and, as it is far away from sources, 
the spatiotemporal variation of $\mathrm{CH}_{4}$ over the ocean is smaller. Some error is attributed to the use of the monthly mean averaging kernels to convolve the aircraft measurements, and this error is estimated to be less than $0.6 \%$. Nevertheless, the averaging kernels will have to be included in the output in future versions of the NOAA CLASS system in order to allow for a more accurate validation.

Possible reasons for the negative bias may include the uncertainty in the spectroscopy near the methane $Q$ branch, errors in the RTA, cloud contamination in the cloud-cleared radiances, and/or the empirical bias correction. Errors in the water vapor (and the temperature) that were retrieved in previous steps also propagate to the $\mathrm{CH}_{4}$ retrieval. An empirical bias correction will be considered using HIPPO and other aircraft measurement data in the next version of the IASI retrieval algorithm.

This algorithm is being used by NOAA/NESDIS to exploit the Cross-track Infrared Sounder (CrIS) to generate $\mathrm{CH}_{4}$ and other carbon products routinely at NOAA. Use of the second IASI instrument on MetOp-B, which was successfully launched on 17 September 2012, will ensure continuity of the IASI product in the future. A combination of AIRS, IASI and CrIS will enable us to achieve $20+$ years of data, which, as supplementary data to current observations from groundbased networks and aircraft measurements, will help us to describe the 3-D distribution of $\mathrm{CH}_{4}$ with a better spatial coverage and to better understand the $\mathrm{CH}_{4}$ emissions and transport in the Arctic.

Ongoing research will focus on optimizing the $\mathrm{CH}_{4}$ retrieval algorithm to generate a consistent product from these three sensors. Further validation/comparison using other satellites (e.g., GOSAT, TES) and in situ ground-based and aircraft measurements will be necessary. Comparison of NOAA IASI product with the EUMETSAT product will be helpful. However, differences between NOAA and EUMETSAT products can be due to the difference in the retrieval method, use of the a priori information, radiative transfer model and the input temperature and water vapor profiles. This will be a topic of future research. We also plan to work with modelers to assimilate these TIR $\mathrm{CH}_{4}$ observations into models to better quantify the $\mathrm{CH}_{4}$ sources and sinks. However, there is much work to be done to utilize these data properly in data assimilation.

Acknowledgements. This research was supported by funding from NOAA Product System Development and Implementation (PSDI) program. The views, opinions, and findings contained in this paper are those of the authors and should not be construed as an official National Oceanic and Atmospheric Administration or US Government position, policy, or decision.

Edited by: D. Brunner

\section{References}

Aumann, H. H., Chahine, M. T., Gautier, C., Goldberg, M. D., Kalnay, E., McMillin, L. M., Revercomb, H., Rosenkranz, P. W., Smith, W. L., Staelin, D. H., Strow, L. L., and Susskind, J.: AIRS/AMSU/HSB on the aqua mission: Design, science objectives, data products, and processing systems, IEEE T. Geosci. Remote, 41, 253-264, 2003.

Bousquet, P., Ciais, P., Miller, J. B., Dlugokencky, E. J., Hauglustaine, D. A., Prigent, C., van der Werf, G. R., Peylin, P., Brunke, E. G., Carouge, C., Langenfelds, R. L., Lathière, J., Papa, F., Ramonet, M., Schmidt, M., Steele, L. P., Tyler, S. C., and White, J.: Contribution of anthropogenic and natural sources to atmospheric methane variability, Nature, 443, 439443, doi:10.1038/nature05132, 2006.

Bousquet, P., Ringeval, B., Pison, I., Dlugokencky, E. J., Brunke, E.G., Carouge, C., Chevallier, F., Fortems-Cheiney, A., Frankenberg, C., Hauglustaine, D. A., Krummel, P. B., Langenfelds, R. L., Ramonet, M., Schmidt, M., Steele, L. P., Szopa, S., Yver, C., Viovy, N., and Ciais, P.: Source attribution of the changes in atmospheric methane for 2006-2008, Atmos. Chem. Phys., 11, 3689-3700, doi:10.5194/acp-11-3689-2011, 2011.

Brasseur, G. P., Hauglustaine, D. A., Walters, S., Rasch, P. J., Müller, J. F., Granier, C., and Tie, X. X.: MOZART, a global chemical transport model for ozone and related chemical tracers 1. Model description, J. Geophys. Res., 103, 28265-28290, doi:10.1029/98jd02397, 1998.

Chen, Y.-H. and Prinn, R. G.: Estimation of atmospheric methane emissions between 1996 and 2001 using a three-dimensional global chemical transport model, J. Geophys. Res., 111, D10307, doi:10.1029/2005jd006058, 2006.

Clerbaux, C., Hadji-Lazaro, J., Turquety, S., Mégie, G., and Coheur, P.-F.: Trace gas measurements from infrared satellite for chemistry and climate applications, Atmos. Chem. Phys., 3, 14951508, doi:10.5194/acp-3-1495-2003, 2003.

Crevoisier, C., Nobileau, D., Fiore, A. M., Armante, R., Chédin, A., and Scott, N. A.: Tropospheric methane in the tropics - first year from IASI hyperspectral infrared observations, Atmos. Chem. Phys., 9, 6337-6350, doi:10.5194/acp-9-6337-2009, 2009.

Crevoisier, C., Nobileau, D., Armante, R., Crépeau, L., Machida, T., Sawa, Y., Matsueda, H., Schuck, T., Thonat, T., Pernin, J., Scott, N. A., and Chédin, A.: The 2007-2011 evolution of tropical methane in the mid-troposphere as seen from space by MetOpA/IASI, Atmos. Chem. Phys., 13, 4279-4289, doi:10.5194/acp13-4279-2013, 2013.

De Mazière, M., Vigouroux, C., Bernath, P. F., Baron, P., Blumenstock, T., Boone, C., Brogniez, C., Catoire, V., Coffey, M., Duchatelet, P., Griffith, D., Hannigan, J., Kasai, Y., Kramer, I., Jones, N., Mahieu, E., Manney, G. L., Piccolo, C., Randall, C., Robert, C., Senten, C., Strong, K., Taylor, J., Tétard, C., Walker, K. A., and Wood, S.: Validation of ACE-FTS v2.2 methane profiles from the upper troposphere to the lower mesosphere, Atmos. Chem. Phys., 8, 2421-2435, doi:10.5194/acp-8-2421-2008, 2008.

Dlugokencky, E. J., Houweling, S., Bruhwiler, L., Masarie, K. A., Lang, P. M., Miller, J. B., and Tans, P. P.: Atmospheric methane levels off: Temporary pause or a new steady-state?, Geophys. Res. Lett., 30, 1992, doi:10.1029/2003g1018126, 2003. 
Dlugokencky, E. J., Myers, R. C., Lang, P. M., Masarie, K. A., Crotwell, A. M., Thoning, K. W., Hall, B. D., Elkins, J. W., and Steele, L. P. : Conversion of NOAA atmospheric dry air $\mathrm{CH}_{4}$ mole fractions to a gravimetrically prepared standard scale, J. Geophys. Res., 110, D18306, doi:10.1029/2005JD006035, 2005.

Dlugokencky, E. J., Bruhwiler, L., White, J. W. C., Emmons, L. K., Novelli, P. C., Montzka, S. A., Masarie, K. A., Lang, P. M., Crotwell, A. M., Miller, J. B., and Gatti, L. V.: Observational constraints on recent increases in the atmospheric $\mathrm{CH}_{4}$ burden, Geophys. Res. Lett., 36, L18803, doi:10.1029/2009g1039780, 2009.

Frankenberg, C., Bergamaschi, P., Butz, A., Houweling, S., Meirink, J. F., Notholt, J., Petersen, A. K., Schrijver, H., Warneke, T., and Aben, I.: Tropical methane emissions: A revised view from SCIAMACHY onboard ENVISAT, Geophys. Res. Lett., 35, L15811, doi:10.1029/2008g1034300, 2008.

Frankenberg, C., Aben, I., Bergamaschi, P., Dlugokencky, E. J., van Hees, R., Houweling, S., van der Meer, P., Snel, R., and Tol, P.: Global column-averaged methane mixing ratios from 2003 to 2009 as derived from SCIAMACHY: Trends and variability, J. Geophys. Res., 116, D04302, doi:10.1029/2010jd014849, 2011.

IPCC: Climate Change 2007: The Physical Science Basis, in: Contribution of Working Group I to the Fourth Assessment Report of the Intergovernmental Panel on Climate Change, edited by: Solomon, S., Qin, D., Manning, M., Chen, Z., Marquis, M., Averyt, K. B., Tignor, M., and Miller, H. L., Cambridge University Press, Cambridge, UK and New York, NY, USA, 2007.

Kort, E. A., Wofsy, S. C., Daube, B. C., Diao, M., Elkins, J. W., Gao, R. S., Hintsa, E. J., Hurst, D. F., Jimenez, R., Moore, F. L., Spackman, J. R., and Zondlo, M. A.: Atmospheric observations of Arctic Ocean methane emissions up to $82^{\circ}$ north, Nat. Geosci., 5, 318-321, doi:10.1038/ngeo1452, 2012.

Maddy, E. S. and Barnet, C. D.: Vertical Resolution Estimates in Version 5 of AIRS Operational Retrievals, IEEE T. Geosci. Remote, 46, 2375-2384, doi:10.1109/tgrs.2008.917498, 2008.

Maddy, E. S., Barnet, C. D., and Gambacorta, A.: A Computationally Efficient Retrieval Algorithm for Hyperspectral Sounders Incorporating A Priori Information, IEEE Geosci. Remote Sens. Lett., 6, 802-806, doi:10.1109/lgrs.2009.2025780, 2009.

Maddy, E. S., King, T. S., Sun, H., Wolf, W. W., Barnet, C. D., Heidinger, A., Cheng, Z., Goldberg, M. D., Gambacorta, A., Zhang, C., and Zhang, K.: Using MetOp-AAVHRR Clear-Sky Measurements to Cloud-ClearMetOp-AIASI Column Radiances, J. Atmos. Ocean. Tech., 28, 1104-1116, doi:10.1175/jtech-d-1005045.1, 2011.

Maddy, E. S., DeSouza-Machado, S. G., Nalli, N. R., Barnet, C. D., Strow, L., Wolf, W. W., Xie, H., Gambacorta, A., King, T. S., Joseph, E., Morris, V., Hannon, S. E., and Schou, P.: On the effect of dust aerosols on AIRS and IASI operational level 2 products, Geophys. Res. Lett., 39, L10809, doi:10.1029/2012g1052070, 2012.

McMillan, W. W., Evans, K. D., Barnet, C. D., Maddy, E. S., Sachse, G. W., and Diskin, G. S.: Validating the AIRS Version 5 CO Retrieval With DACOM In Situ Measurements During INTEX-A and -B, IEEE T. Geosci. Remote, 49, 2802-2813, doi:10.1109/tgrs.2011.2106505, 2011.

Park, M., Randel, W. J., Kinnison, D. E., Garcia, R. R., and Choi, W.: Seasonal variation of methane, water vapor, and nitrogen oxides near the tropopause: Satellite observations and model simulations, J. Geophys. Res., 109, D03302, doi:10.1029/2003jd003706, 2004.

Parker, R., Boesch, H., Cogan, A., Fraser, A., Feng, L., Palmer, P. I., Messerschmidt, J., Deutscher, N., Griffith, D. W. T., Notholt, J., Wennberg, P. O., and Wunch, D.: Methane observations from the Greenhouse Gases Observing SATellite: Comparison to groundbased TCCON data and model calculations, Geophys. Res. Lett., 38, L15807, doi:10.1029/2011GL047871, 2011.

Patra, P. K., Houweling, S., Krol, M., Bousquet, P., Belikov, D., Bergmann, D., Bian, H., Cameron-Smith, P., Chipperfield, M. P., Corbin, K., Fortems-Cheiney, A., Fraser, A., Gloor, E., Hess, P., Ito, A., Kawa, S. R., Law, R. M., Loh, Z., Maksyutov, S., Meng, L., Palmer, P. I., Prinn, R. G., Rigby, M., Saito, R., and Wilson, C.: TransCom model simulations of $\mathrm{CH}_{4}$ and related species: linking transport, surface flux and chemical loss with $\mathrm{CH}_{4}$ variability in the troposphere and lower stratosphere, Atmos. Chem. Phys., 11, 12813-12837, doi:10.5194/acp-11-12813-2011, 2011. Payan, S., Camy-Peyret, C., Oelhaf, H., Wetzel, G., Maucher, G., Keim, C., Pirre, M., Huret, N., Engel, A., Volk, M. C., Kuellmann, H., Kuttippurath, J., Cortesi, U., Bianchini, G., Mencaraglia, F., Raspollini, P., Redaelli, G., Vigouroux, C., De Mazière, M., Mikuteit, S., Blumenstock, T., Velazco, V., Notholt, J., Mahieu, E., Duchatelet, P., Smale, D., Wood, S., Jones, N., Piccolo, C., Payne, V., Bracher, A., Glatthor, N., Stiller, G., Grunow, K., Jeseck, P., Te, Y., and Butz, A.: Validation of version-4.61 methane and nitrous oxide observed by MIPAS, Atmos. Chem. Phys., 9, 413-442, doi:10.5194/acp-9-413-2009, 2009.

Payne, V. H., Clough, S. A., Shephard, M. W., Nassar, R., and Logan, J. A.: Information-centered representation of retrievals with limited degrees of freedom for signal: Application to methane from the Tropospheric Emission Spectrometer, J. Geophys. Res., 114, D10307, doi:10.1029/2008jd010155, 2009.

Razavi, A., Clerbaux, C., Wespes, C., Clarisse, L., Hurtmans, D., Payan, S., Camy-Peyret, C., and Coheur, P. F.: Characterization of methane retrievals from the IASI space-borne sounder, Atmos. Chem. Phys., 9, 7889-7899, doi:10.5194/acp-9-7889-2009, 2009.

Rigby, M., Prinn, R. G., Fraser, P. J., Simmonds, P. G., Langenfelds, R. L., Huang, J., Cunnold, D. M., Steele, L. P., Krummel, P. B., Weiss, R. F., O'Doherty, S., Salameh, P. K., Wang, H. J., Harth, C. M., Mühle, J., and Porter, L. W.: Renewed growth of atmospheric methane, Geophys. Res. Lett., 35, L22805, doi:10.1029/2008g1036037, 2008.

Rodgers, C. D.: Inverse Methods for Atmospheric Sounding: Theory and Practice, University of Oxford, World Sci., River Edge, NJ, USA, 2000.

Schepers, D., Guerlet, S., Butz, A., Landgraf, J., Frankenberg, C., Hasekamp, O., Blavier, J. F., Deutscher, N. M., Griffith, D. W. T., Hase, F., Kyro, E., Morino, I., Sherlock, V., Sussmann, R., and Aben, I.: Methane retrievals from Greenhouse Gases Observing Satellite (GOSAT) shortwave infrared measurements: Performance comparison of proxy and physics retrieval algorithms, J. Geophys. Res., 117, D10307, doi:10.1029/2012jd017549, 2012.

Shakhova, N., Semiletov, I., Salyuk, A., Yusupov, V., Kosmach, D., and Gustafsson, Ö.: Extensive Methane Venting to the Atmosphere from Sediments of the East Siberian Arctic Shelf, Science, 327, 1246-1250, doi:10.1126/science.1182221, 2010. 
Simpson, I. J., Chen, T.-Y., Blake, D. R., and Rowland, F. S.: Implications of the recent fluctuations in the growth rate of tropospheric methane, Geophys. Res. Lett., 29, 1479, doi:10.1029/2001g1014521, 2002.

Strow, L. L., Hannon, S. E., De Souza-Machado, S., Motteler, H. E., and Tobin, D.: An overview of the AIRS radiative transfer model, IEEE T. Geosci. Remote, 41, 303-313, 2003.

Susskind, J., Barnet, C. D., and Blaisdell, J. M.: Retrieval of atmospheric and surface parameters from AIRS/AMSU/HSB data in the presence of clouds, IEEE T. Geosci. Remote, 41, 390-409, doi:10.1109/tgrs.2002.808236, 2003.

Sussmann, R., Forster, F., Rettinger, M., and Bousquet, P.: Renewed methane increase for five years (2007-2011) observed by solar FTIR spectrometry, Atmos. Chem. Phys., 12, 4885-4891, doi:10.5194/acp-12-4885-2012, 2012.

Wecht, K. J., Jacob, D. J., Wofsy, S. C., Kort, E. A., Worden, J. R., Kulawik, S. S., Henze, D. K., Kopacz, M., and Payne, V. H.: Validation of TES methane with HIPPO aircraft observations: implications for inverse modeling of methane sources, Atmos. Chem. Phys., 12, 1823-1832, doi:10.5194/acp-12-1823-2012, 2012.

Wofsy, S. C. and the HIPPO Science Team and Cooperating Modellers and Satellite Teams: HIAPER Pole-to-Pole Observations (HIPPO): fine-grained, global-scale measurements of climatically important atmospheric gases and aerosols, Philos. T. Roy. Soc. A, 369, 2073-2086, doi:10.1098/rsta.2010.0313, 2011.

Worden, J., Kulawik, S., Frankenberg, C., Payne, V., Bowman, K., Cady-Peirara, K., Wecht, K., Lee, J.-E., and Noone, D.: Profiles of $\mathrm{CH}_{4}, \mathrm{HDO}, \mathrm{H}_{2} \mathrm{O}$, and $\mathrm{N}_{2} \mathrm{O}$ with improved lower tropospheric vertical resolution from Aura TES radiances, Atmos. Meas. Tech., 5, 397-411, doi:10.5194/amt-5-397-2012, 2012.
Xiong, X., Barnet, C., Maddy, E., Sweeney, C., Liu, X., Zhou, L., and Goldberg, M.: Characterization and validation of methane products from the Atmospheric Infrared Sounder (AIRS), J. Geophys. Res., 113, G00A01, doi:10.1029/2007jg000500, 2008.

Xiong, X., Houweling, S., Wei, J., Maddy, E., Sun, F., and Barnet, C.: Methane plume over south Asia during the monsoon season: satellite observation and model simulation, Atmos. Chem. Phys., 9, 783-794, doi:10.5194/acp-9-783-2009, 2009.

Xiong, X., Barnet, C., Maddy, E., Wei, J., Liu, X., and Pagano, T. S.: Seven Years' Observation of Mid-Upper Tropospheric Methane from Atmospheric Infrared Sounder, Remote Sensing, 2, 2509 2530, doi:10.3390/rs2112509, 2010a.

Xiong, X., Barnet, C. D., Zhuang, Q., Machida, T., Sweeney, C., and Patra, P. K.: Mid-upper tropospheric methane in the high Northern Hemisphere: Spaceborne observations by AIRS, aircraft measurements, and model simulations, J. Geophys. Res., 115, D19309, doi:10.1029/2009JD013796, 2010b.

Yokota, T., Yoshida, Y., Eguchi, N., Ota, Y., Tanaka, T., Watanabe, H., and Maksyutov, S.: Global concentrations of $\mathrm{CO}_{2}$ and $\mathrm{CH}_{4}$ retrieved from GOSAT: First preliminary results, SOLA, 5, 160163, 2009.

Zhuang, Q., Melack, J. M., Zimov, S., Walter, K. M., Butenhoff, C. L., and Khalil, M. A. K.: Global Methane Emissions From Wetlands, Rice Paddies, and Lakes, EOS T. Am. Geophys. Union, 90, 37-38, doi:10.1029/2009eo050001, 2009.

Zimov, S. A., Davydov, S. P., Zimova, G. M., Davydova, A. I., Schuur, E. A. G., Dutta, K., and Chapin, F. S.: Permafrost carbon: Stock and decomposability of a globally significant carbon pool, Publication: Geophys. Res. Lett., 33, L20502, doi:10.1029/2006g1027484, 2006. 